\title{
FORMULASI DAN EVALUASI FISIK SEDIAAN EMULGEL TABIR SURYA EKSTRAK KULIT BATANG KAYU MANIS (Cinnamomum burmannii)
}

\author{
Risqika Yuliatantri Paramawidhita ${ }^{1}$, Uswatun Chasanah ${ }^{2}$, Dian Ermawati ${ }^{2}$ \\ ${ }^{1}$ Program Studi D3 Farmasi Fakultas IImu Kesehatan \\ Universitas Muhammadiyah Palangkaraya \\ Palangka Raya, Kalimantan Tengah \\ ${ }^{2}$ Program Studi S1 Farmasi Fakultas IImu Kesehatan \\ Universitas Muhammadiyah Malang, Malang Indonesia
}

\begin{abstract}
ABSTRAK
Salah satu bahan alami yang bisa digunakan untuk tabir surya adalah Cinnamomum burmannii. Kandungan kimia sinamaldehid dalam ekstrak kulit kayu manis yang berpotensi sebagai antioksidan dan dapat digunakan sebagai kandungan tabir surya. Penelitian ini adalah untuk melihatkadar ekstrak kulit kayu manis $(1 \%, 2 \%$ dan $3 \%)$ yang dapat memberikan karakteristik fisik dan akseptabilitas yang optimal dengan HPMC sebagai agen pembentuk gel.Evaluasi meliputi $\mathrm{pH}$, daya sebar, viskositas dan akseptabilitas sediaan. Hasil organoleptis untuk formula I (1\%), II (2\%) dan III (3\%) memiliki tekstur lembut berbintik, aroma kayu manis yang khas, dan semua formula memiliki warna coklat pucat. Dari analisis One-Way ANOVA menemukan perbedaan yang signifikan untuk daya sebar.Tetapi tidak memiliki perbedaan yang signifikan dalam $\mathrm{pH}$ dan viskositas. Untuk evaluasi akseptabilitas, formula III adalah formula optimal untuk kelembutan diaplikasikan, formula paling mudah untuk diratakan dan mudah dicuci.
\end{abstract}

Kata Kunci :ekstrak kulit batang kayu manis, emulgel, evaluasi fisik

\begin{abstract}
One of the natural ingredient can be used for sunscreen is Cinnamomum burmannii. Sinamaldehid chemical constituents in cinnamon bark extract that has potential as an antioxidant and can be used as a sunscreen content. This study was to determine the levels of cinnamon bark extract ( $1 \%, 2 \%$ and $3 \%$ ) which can give physical characteristics, acceptability, which is optimal for preparations with HPMC as a gelling agent, Evaluations include $\mathrm{pH}$, the power spread, the viscosity and acceptability. The results of organoleptic for formula I (1\%), II (2\%) and III (3\%) have a soft texture grainy, distinctive smell of cinnamon, and all formula has a pale brown color. From the analysis of One-Way ANOVA found significant differences for any dispersive power. But did not have significant differences in $\mathrm{pH}$ and viscosity. For acceptability evaluation formula III is the optimal formula to applied softnes, easiest formula to flattened and easy to wash.
\end{abstract}

Keywords : cinnamon bark extract, emulgel ,physic evaluation 


\section{PENDAHULUAN}

Sediaan tabir surya merupakan salah satu sediaan kosmetika yang digunakan dengan tujuan melindungi kulit dari paparan radiasi sinar matahari dan memiliki dua mekanisme yaitu dengan memantulkan dan menyerap sinar UV secara efektif sehingga dapat mencegah terjadinya gangguan kulit [1]. Senyawa antioksidan dapat meredam efek oksidatif dari reactive oxygen species (ROS) yang muncul akibat radiasi sinar UV [2].

Kayu manis (Cinnamomum burmannii) merupakan salah satu tanaman obat yang banyak dibudidayakan di Indonesia yang memiliki banyak khasiat bagi kesehatan. Salah satu kelebihan yang dimiliki oleh kulit batang kayu manis adalah memiliki aktivitas tabir surya dan antioksidan sekaligus [3]. Hal tersebut menjadikan kulit batang kayu manis potensial untuk dijadikan bahan aktif pada sediaan tabir surya. Kandungan kimia dalam kulit batang kayu manis diantaranya sinamaldehid, asam sinamat, kumarin, tanin, dan flavanoid. Senyawa-senyawa tersebut diketahui berpotensi sebagai antioksidan serta dapat digunakan sebagai kandungan sediaan tabir surya karena mampu menyerap radiasi sinar ultraviolet pada panjang gelombang daerah UV-B [4].

Untuk kemudahan penggunaan pada kulit, maka kulit batang kayu manis perlu diformulasi menjadi suatu sediaan farmasi. Sediaan semisolid dalam industri farmasi dapat berupa krim, gel, salep, ointment dan lotion. Bentuk sediaan yang dipilih adalah emulgel. Emulgel merupakan salah satu bentuk sediaan kulit yang merupakan gabungan dari sediaan emulsi dan gel. Sediaan emulgel disebut juga sebagai sediaan emulsi yang viskositas fase airnya ditingkatkan melalui penambahan gelling agent. Kelebihan dari sediaan emulgel ini adalah nyaman digunakan dan mampu melekat pada waktu yang relatif lama pada kulit sehingga dapat mendukung penggunaannya sebagai sediaan tabir surya [5].

Dari pertimbangan yang ada, maka pada penelitian ini akan diformulasikan sediaan emulgel tabir surya yang mengandung ekstrak kulit batang kayu manis dengan konsentrasi 1\%, $2 \%, 3 \%$. Untuk evaluasi sediaan dilakukan penentuan karakteristik fisik dengan evaluasi penetapan $\mathrm{pH}$, viskositas, daya sebar, dan aseptabilitassediaan emulgel tabir 
surya ekstrak kulit batang kayu manis (Cinnamomum burmannii).

\section{METODE PENELITIAN}

\section{A. Bahan}

Bahan penelitian yang digunakan yaitu ekstrak kulit batang kayu manis (Cinnamomum burmannii) diperoleh dari UPT. Balai Materia Medika Batu-Malang, Parrafin Liquidum, Tween 80, Span 80, Propylenglycol, Methylparaben, Propylparaben, dan Aquadest.

\section{B. Alat}

Alat-alat yang digunakan dalam penelitian ini meliputi $\mathrm{pH}$ meter Basic
20 (Crison), neraca analitik digital (Metler Toledo), peralatan uji daya sebar, peralatan uji viskositas, (Rion Viscotester vT-045F), Steroglasshot plate (DAIHAN LABTECH CO.,LTD), cawan petri, mortir, stamper dan alatalat gelas.

\section{Pembuatan Sediaan Emulgel Tabir Surya Ekstrak Kulit Batang Kayu Manis}

Komposisi sediaan emulgel ekstrak kulit batang kayu manis dengan basis HPMC dengan kadar 1 $\%$, $2 \%$ dan $3 \%$ dapat dilihat pada Tabel

Tabel 1 Komposisi Sediaan Emulgel Ekstrak Kulit Batang kayu Manis dengan kadar $1 \%$ (Formula I), 2 \% (Formula II) dan 3 \% (Formula III)

\begin{tabular}{|c|c|c|c|}
\hline & \multicolumn{3}{|c|}{ Formula Emulgel } \\
\hline Bahan & Formula I & Formula II & Formula III \\
\hline Ekstrak kayu manis & 2 & 4 & 6 \\
\hline Paraffin Liquidum & 10 & 10 & 10 \\
\hline Methyl paraben & 0,4 & 0,4 & 0,4 \\
\hline Propyl paraben & 0,6 & 0,6 & 0,6 \\
\hline Tween 80 & 20 & 20 & 20 \\
\hline Span 80 & 20 & 20 & 20 \\
\hline Propylenglycol & 20 & 20 & 20 \\
\hline HPMC & 6 & 6 & 6 \\
\hline Aquadest & Ad $200 \mathrm{~g}$ & Ad $200 \mathrm{~g}$ & Ad $200 \mathrm{~g}$ \\
\hline
\end{tabular}

Cara Pembuatan Emulgel Tabir Surya Ekstrak Kulit Batang Kayu Manis Sebagai Berikut:
Dimulai dari mencampurkan semua fase minyak yaitu span 80 dicampur dengan paraffin liq 
kemudian dilebur pada suhu $70^{\circ} \mathrm{C}$, kemudian fase air yaituTween 80 yang telah dilarutkan denganaquadest panas. Kemudian fase air dimasukkan ke dalam fase minyak pada suhu $70^{\circ} \mathrm{C}$ sambil terus diaduk sampai terbentuk emulsi.Fase gelling yaitu HPMC dilarutkan dengan air panas di dalam mortir diaduk sampai terbentuk basis gel.Metil paraben dan propil paraben dilarutkan dalam propilenglikol, lalu dicampurkan dengan basis gel. Kemudian emulsi yang telah terbentuk dimasukkan ke dalam mortir dan diaduk konstan sampai terbentuk emulgel yang baik kemudian setelah keadaan emulgel hangat ditambahkan ekstrak.

\section{Evaluasi Sediaan}

\subsection{Karakteristik Sediaan}

\subsubsection{Pemeriksaan} OrganoleptisSediaan Emulgel Tabir Surya Ekstrak Kulit Batang Kayu Manis

Pemeriksaan organoleptis yang dilakukan meliputi warna, bau dan tekstur.Tekstur yang diamati adalah konsistensi dari sediaan ${ }^{(6)}$.

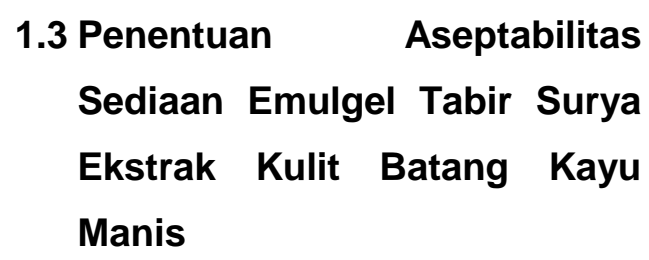

\subsubsection{Pengukuran Daya Sebar Sediaan Emulgel Tabir Surya Ekstrak Kulit Batang Kayu Manis \\ Emulgel sebanyak 2 gram}

diletakkan di atas kaca transparan yang beralaskan kertas grafik, kemudian ditutup dengan lempeng kaca dan diberi beban $(0 \mathrm{~g}, 1 \mathrm{~g}, 2 \mathrm{~g}$, 3 g, 4 g, 5 g) kemudian ukur diameter penyebaran ${ }^{(7)}$.

\subsubsection{Pengukuran Viskositas Sediaan Emulgel \\ Pengukuran viskositas} sediaan dilakukan menggunakan alat viscometer cup and bob.Pertama alat viskometer dinyalakan, kemudian memilih rotor yang sesuai lalu sediaan dimasukkan ke dalam rotor.Rotor dipasang pada alat, tombol pemutar alat dinyalakan, lalu jarum penunjuk viskositas dibaca.

\subsection{Pengukuran pH Sediaan \\ Emulgel Tabir Surya Ekstrak Kulit Batang Kayu Manis}

Pengukuran $\mathrm{pH}$ sediaan dilakukan dengan alat $\mathrm{pH}$ meter Basic

$20^{+}$ 
sediaan tersebut. Jumlah responden 10 orang perempuan dengan usia 20-23 tahun yang dipilih secara random atau acak. Evaluasi aseptabilitas sediaan meliputi kelembutan emulgel dioleskan, kemudahan emulgel diratakan dan kemudahan dicuci. Responden menggunakan emulgel tabir surya ekstrak kulit batang kayu manis (Cinnamomum burmanii) pada permukaan kulit dan diminta pendapatnya tentang kelembutan emulgel dioleskan, kemudahan emulgel diratakan dan kemudahan dicuci. Untuk kritria penilaiannya responden akan memberikan nilai, sebagai berikut :

1. Kelembutan dioleskan dengan skor untuk kasar $=1$; tidak lembut $=2$; lembut $=3$; dan sangat lembut $=4$.

2. Kemudahan diratakan dengan skor untuk tidak bisa diratakan = 1 ; sangat sulit diratakan $=2$; mudah rata $=3$; sangat mudah rata $=4$.

3. Kemudahan dicuci dengan skor untuk tidak bisa dicuci $=1$; sulit dicuci $=2 ;$ mudah dicuci $=3$; dan sangat mudah dicuci $=4$.

\section{E. Analisis Data}

Analisa data pada pemeriksaan organoleptis dilakukan secara visual dengan mengamati sediaan secara langsung meliputi bau, warna dan tekstur yang dilakukan satu hari setelah pembuatan.

Untuk analisa uji karakteristik fisik dan aseptabilitas sediaan menggunakan uji One-way Anova. Dari data yang didapatkan dilakukan analisa statistik dengan derajat kepercayaan $\alpha=0,05$. Untuk mengetahui formula mana yang terdapat perbedaan bermakna dilihat dari harga $F$ hitung dan $F$ tabel. Apabila hasil yang diperoleh $\mathrm{F}$ hitung $>\mathrm{F}$ tabel menunjukkan adanya perbedaan bermakna, sehingga dilanjutkan dengan uji HSD (Honestly Significant Difference) untuk mgetahui data mana yang berbeda.

\section{HASIL DAN PEMBAHASAN}

\section{A. Hasil Pemeriksaan Organoleptis Sediaan Emulgel Tabir Surya Ekstrak Kulit Batang Kayu Manis}

Hasil pemeriksaan organoleptis sediaan emulgel tabir surya ekstrak kulit batang kayu manis dapat diketahui bahwa formula I, II dan III memiliki tekstur yang lembut berbintik, beraroma kayu manis dan mempunyai warna yang sama yaitu coklat muda pucat (Gambar 1). 


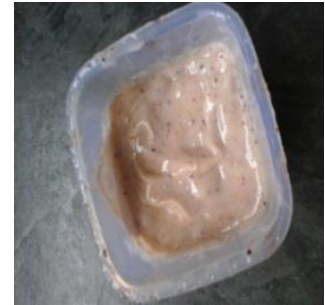

Gambar 1. Organoleptis Sediaan Emulgel Ekstrak Kulit Batang Kayu Manis

\section{B. Pengukuran Viskositas Sediaan Emulgel Tabir Surya Ekstrak Kulit Batang Kayu Manis}

Hasil pengukuran viskositas sediaan emulgel ekstrak kulit batang kayu manis dapat dilihat pada Tabel 2. Pemeriksaan viskositas dilakukan sehari setelah pembuatan sediaan emulgel masing-masing formula, diperoleh hasil formula I $(1786,67 \pm$ 400,67 dPas), formula II (2226,67 \pm 688,57 dPas) dan formula III (2400 \pm 1139,12 dPas). Untuk mengetahui adanya pengaruh peningkatan kadar ekstrak kulit batang kayu manis (Cinnamomum burmannii) yang digunakan pada sediaan dilakukan analisis statistik dengan One-Way Anova. Dari hasil analisis didapatkan harga $F$ hitung $(0,466)<F$ tabel $(5,143)$ dengan derajat kepercayaan $\alpha=0,05$, yang berarti bahwa tidak terdapat perbedaan viskositas yang bermakna.

Tabel 2. Viskositas Sediaan Emulgel $1 \%$ (Formula I), 2 \% (Formula II) dan 3 \% (Formula III)

\begin{tabular}{ccccc}
\hline & \multicolumn{3}{c}{ Replikasi } & \\
\cline { 2 - 4 } Formula & 1 & 2 & 3 & Rerata \pm SD \\
\hline I & 1480 & 1640 & 2240 & $1786,67 \pm 400,67$ \\
II & 1680 & 3000 & 2000 & $2226,67 \pm 688,57$ \\
III & 3400 & 2640 & 1160 & $2400 \quad \pm$ \\
& & & & 1139,12 \\
\hline
\end{tabular}

C. Pengukuran Daya Sebar Sediaan Emulgel Tabir Surya Ekstrak Kulit Batang

\section{Kayu Manis}

Hasil pengukuran daya sebar sediaan emulgel ekstrak kulit batang kayu manis dapat dilihat pada Tabel 3. Uji daya sebar sediaan emulgel tabir surya dari masing-masing formula, diperoleh formula I $(0,34 \pm$ $0,08 \mathrm{~g} / \mathrm{cm})$, formula II $(0,28 \pm 0,02$ $\mathrm{g} / \mathrm{cm})$ dan formula III $(0,18 \pm 0,05$ $\mathrm{g} / \mathrm{cm})$. Untuk mengetahui adanya pengaruh peningkatan kadar ekstrak kulit batang kayu manis (Cinnamomum burmannii) yang digunakan pada sediaan terhadap daya sebar sediaan emulgel 
dilakukan analisis statistik dengan

One-Way Anova, didapatkan harga

$F$ hitung $(6,189)>F$ tabel $(5,143)$

dengan derajat kepercayaan $\alpha=$ 0,05 yang berarti bahwa terdapat perbedaan daya sebar yang bermakna. Untuk mengetahui signifikansi perbedaan tiap formula dilakukan uji HSD didapatkan formula III memiliki nilai yang rendah dari formula II dan formula I, dan formula II memiliki nilai yang rendah dari formula I, dengan demikian dapat disimpulkan bahwa peningkatan kadar antara formula I, II dan III mempengaruhi daya sebar sediaan emulgel.

Tabel 3. Hasil Pengukuran Daya Sebar Sediaan Emulgel Tabir Surya Ekstrak Kulit Batang Kayu Manis $1 \%$ (Formula I), 2 \% (Formula II) dan $3 \%$ (Formula III)

\begin{tabular}{|c|c|c|c|c|}
\hline Formula & Replikasi & Persamaan & $\begin{array}{l}\text { Daya Sebar } \\
(\mathrm{g} / \mathrm{cm})\end{array}$ & Rerata \pm SD \\
\hline \multirow[t]{4}{*}{ I } & 1 & $\begin{array}{c}\mathrm{Y}=0,44 \mathrm{x}+7,66 \\
\mathrm{R}=0,9969\end{array}$ & 0,44 & \\
\hline & 2 & $\begin{array}{c}Y=0,29 x+8,77 \\
R=0,9935\end{array}$ & 0,29 & $0,34 \pm 0,08$ \\
\hline & 3 & $\begin{array}{c}Y=0,31 x+8,05 \\
R=0,9862\end{array}$ & 0,31 & \\
\hline & 1 & $\begin{array}{c}Y=0,31 x+8,27 \\
R=0,9902\end{array}$ & 0,31 & \\
\hline \multirow[t]{3}{*}{ II } & 2 & $\begin{array}{c}Y=0,26 x+8,14 \\
R=0,9912\end{array}$ & 0,26 & $0,28 \pm 0,02$ \\
\hline & 3 & $\begin{array}{c}Y=0,29 x+10,09 \\
R=0,9820\end{array}$ & 0,29 & \\
\hline & 1 & $\begin{array}{c}Y=0,24 x+6,98 \\
R=0,9965\end{array}$ & 0,24 & \\
\hline \multirow[t]{2}{*}{ III } & 2 & $\begin{array}{c}Y=0,15 x+6,87 \\
R=0,9934\end{array}$ & 0,15 & $0,18 \pm 0,05$ \\
\hline & 3 & $\begin{array}{c}Y=0,17 x+7,35 \\
R=0,9948\end{array}$ & 0,17 & \\
\hline
\end{tabular}




\section{Pengukuran pH Sediaan Emulgel Tabir Surya Ekstrak Kulit Batang Kayu Manis}

Hasil pengukuran $\mathrm{pH}$ ekstrak kulit batang kayu manis dapat dilihat pada Tabel 4. Uji pemeriksaan $\mathrm{pH}$ didapatkan menunjukkan rerata \pm simpangan deviasi formula I $(6,79 \pm$ $0,09)$, II $(6,75 \pm 0,23)$ dan III $(6,74 \pm$ 0,05). Kemudian diuji statistik dengan One-Way Anova didapatkan harga $F$ hitung $(0,068)$ lebih kecil dari $F$ tabel $(5,143)$ dengan derajat kepercayaan $\alpha=0,05$, yang berarti bahwa tidak terdapat perbedaan $\mathrm{pH}$ yang bermakna. Dengan demikian dapat disimpulkan bahwa peningkatan berbagai kadar antara formula I, II dan III belum mempengaruhi $\mathrm{pH}$.

Tabel 4. $\mathrm{pH}$ Sediaan Emulgel Ekstrak Kulit Batang Kayu Manis $1 \%$ (Formula I), $2 \%$ (Formula II) dan $3 \%$ (Formula III)

\begin{tabular}{ccccr}
\hline & \multicolumn{3}{c}{ Replikasi } & \\
\cline { 2 - 4 } Formula & 1 & 2 & 3 & Rerata \pm SD \\
\hline I & 6,76 & 6,71 & 6,90 & $6,79 \pm 0,09$ \\
II & 6,81 & 6,96 & 6,50 & $6,75 \pm 0,23$ \\
III & 6,81 & 6,73 & 6,70 & $6,74 \pm 0,05$
\end{tabular}

E. Penentuan Aseptabilitas Sediaan Emulgel Ekstrak Kulit Batang Kayu Manis Hasil Penentuan aseptabilitas sediaan emulgel ekstrak kulit batang kayu manis dapat dilihat pada Tabel 5. Dari hasil uji aseptabilitas yang telah dilakukan didapatkan kesimpulan bahwa formula III memiliki skor terbanyak untuk kriteria paling lembut dioleskan, paling mudah diratakan dan paling mudah dicucikan. Hal ini menunjukkan bahwa formula III yang paling memenuhi kriteria aseptabilitas dari sediaan emulgel tabir surya ekstrak kulit batang kayu manis (Cinnamomum burmannii) yaitu dengan kadar ekstrak $3 \%$. 
Tabel 5. Hasil uji aseptabilitas sediaan emulgel ekstrak kulit batang kayu manis 1 \% (Formula I), 2 \% (Formula II) dan 3 \% (Formula III)

\begin{tabular}{cccc}
\hline \multirow{3}{*}{ Formula } & \multicolumn{3}{c}{$\begin{array}{c}\text { Parameter } \\
\text { Aseptabilitas }(\%)\end{array}$} \\
\cline { 2 - 4 } & $\begin{array}{c}\text { Kelembutan } \\
\text { dioleskan }\end{array}$ & $\begin{array}{c}\text { Kemudahan } \\
\text { diratakan }\end{array}$ & $\begin{array}{c}\text { Kemudahan } \\
\text { dicucikan }\end{array}$ \\
\hline I & 75 & 70 & 75 \\
II & 75 & 75 & 72,5 \\
III & 80 & 82,5 & 80 \\
\hline
\end{tabular}

\section{KESIMPULAN}

Dalam penelitian ini didapatkan viskositas dan $\mathrm{pH}$ sediaan tidak ada perbedaan yang signifikan, kemudian hanya daya sebar yang terdapat perbedaan signifikan.Sedangkan pada uji aseptabilitas, formula III yang lebih disukai responden. Sehingga bisa dikombinasikan dari ketiga formula untuk mendapat hasil yang lebih optimal.

\section{DAFTAR PUSTAKA}

1. Wehantouw, F., Suryanto, E., Kojong, N.N dan Pontoan, J., 2011. Aktivitas Ekstrak Etanol Daun Alpukat (Persea americana M.) Sebagai Krim Tabir Surya. Manado. Kongres Ilmiah Ikatan Apoteker Indonesia ke XIX

2. Hassan, I., Konchok D., Abdul S., Parvaiz A. (2013). Sunscreen and Antioxidants as Photo-Protective Measure: An update, Our Dhermatol Online, Vol. 4, No. 3. pp. 369-374

3. Shekar, M., Shirin S., George L., Karthik M. (2012). Evaluatin of In Vitro Antioxidants Property and Radio Protective Effect of The Constituent Medicinal Plants of a Herbal Sunscreen Formulations, International Journal of Pharmaceutical Frontier Research (IJPFR), Vol. 2, No. 2. pp. 90-96.

4. Prasetya, N.B.A., dan Ngadiwiyana. (2006). 'Identifikasi Senyawa Penyusun Minyak Kulit Batang Kayu Manis (Cinnamomum cassia) Menggunakan GC-MS', Jurnal Sains \& Matematika, Vol.14, No. 1.pp. 28

5. Panwar, A.S. (2011). Emulgel: A Review, Asian Journal of Pharmacy and Life Science, July-Sept, Vol. 1, No. 3. pp. 334.

6. Anief, M. 1997. Ilmu Meracik Obat. Gajah Mada University Press, Yogyakarta 
7. Voight, R, 1994, Buku Pelajaran

Teknologi Farmasi edisi 5,

Gadjah Mada University Press,

Yogyakarta, hal 17. 